Research Article

\title{
Effect of Alkali Seepage Erosion on Physical and Mechanical Properties of Laterite
}

\author{
Yan Li $\mathbb{D}^{1,2,3}$ Yasheng Luo $\mathbb{D}^{1},{ }^{1}$ Songtao $\mathrm{Hu}^{2,3}$ Jianglin Gao, ${ }^{2,3}$ and Chaojie Wang $\mathbb{D}^{4}$ \\ ${ }^{1}$ College of Water Resources and Architectural Engineering, Northwest A \& F University, Yangling 712100, China \\ ${ }^{2}$ Jiangxi Academy of Water Science and Engineering, Nanchang 330029, China \\ ${ }^{3}$ Jiangxi Engineering Technology Research Center on Hydraulic Structures, Nanchang 330029, China \\ ${ }^{4}$ School of Water Science and Engineering, Zhengzhou University, Zhengzhou 450000, China \\ Correspondence should be addressed to Yasheng Luo; lyas1967@nwsuaf.edu.cn
}

Received 26 June 2021; Revised 4 August 2021; Accepted 24 August 2021; Published 1 October 2021

Academic Editor: Xin Cai

Copyright $\odot 2021$ Yan Li et al. This is an open access article distributed under the Creative Commons Attribution License, which permits unrestricted use, distribution, and reproduction in any medium, provided the original work is properly cited.

\begin{abstract}
Using a modified permeameter, laterite samples that were corroded and permeated by alkaline solutions at different concentrations for varying amounts of time were subjected to triaxial compression tests, chemical composition analysis, particle composition tests, and microstructure analysis. The results showed that the strength parameters $c, \varphi$, and $K$ of the laterite samples that were corroded by alkaline-solution permeation were reduced with increasing corrosion time and alkaline-solution concentration. The alkaline-solution corrosion had a minor effect on the strength parameters $n$ and $R_{f}$. The contents of $\mathrm{Al}_{2} \mathrm{O}_{3}$ and $\mathrm{Fe}_{2} \mathrm{O}_{3}$ in the laterite fluctuated and decreased with increasing alkaline-solution concentration and corrosion time. There were no distinct patterns in the relationships between the $\mathrm{SiO}_{2}$ content and the increases in the alkaline-solution concentration and corrosion time. Due to the corrosion during the alkaline-solution permeation, the content of clay particles increased with increasing time and concentration of the alkaline solution. After the permeation with the alkaline solution, the soil particles became smaller and were arranged in an ordered state. The analysis suggested that the permeation effect of the alkaline solution changed the chemical composition of the laterite and the connecting strength of the soil particles, resulting in changes in its physical and mechanical properties.
\end{abstract}

\section{Introduction}

As national awareness of environmental protection increases, geotechnical engineering researchers are paying more attention to the environmental and geotechnical engineering issues associated with environmental science. With the development of the economy, water contamination will inevitably occur in various fields, including mining, chemical industry, and agriculture. The impact of these contaminated water bodies on the soil, foundations, and related geotechnical engineering structures has aroused the interest of environmental and geotechnical engineering researchers. There have been reports on the impact of corrosive or contaminated water on soil, foundations, and buildings. In the Fujian and Shanxi provinces, the infiltration of leaked alkaline waste liquid from paper mills into the foundation soil has caused damage to plant buildings $[1,2]$. The loss of laterite particles caused by alkaline-solution corrosion of cement has resulted in permeation damage to Longlin Reservoir in Dayao County, Yunnan Province.

Laterite is widely distributed in southern China, and researchers have conducted a large number of studies to examine the effects of alkaline solutions on laterite. Li et al. [2] conducted indoor tests on the soil contaminated by waste alkaline solutions from a paper mill. The study showed that, after the corrosion by alkaline solutions, the strength of the soil samples decreased, and the void ratio and compressibility increased. Zhu et al. [3] and Liu et al. [4] studied the compression deformation properties and basic physical properties of alkaline-contaminated soil. The experimental results showed that, with increasing concentration of pollutants, the compression coefficient of alkaline- 
contaminated soil increased considerably, and large changes in the physical properties occurred. Chen [5] studied the changes in the chemical composition, bonding force, and microstructure of laterite during alkaline-solution corrosion and found that the coefficient of compressibility and water permeability of the soil increased after corrosion, as did the shear strength, internal friction angle, and cohesive force. Li [6] tested the physical and mechanical properties of laterite after it had been corroded by calcium hydroxide, and the results showed that the physical and mechanical indicators of laterite exhibited a trend of significant deterioration. The permeability coefficient and compressibility of the sample increased, while the cohesive force, internal friction angle, and clay particle content were reduced. Yang et al. [7-9] also carried out tests on the physical and mechanical properties of laterite after alkali immersion corrosion and measured the changes in the chemical compositions of the soil and the immersion liquid. The results showed that the alkaline solution could allow the internal friction angle and cohesive force of the soil body to be reduced. Zhao [10] showed that laterite could undergo different degrees of chemical corrosion reactions in alkaline solutions. Scanning electron microscopy (SEM) images showed that the pore arrangement tended to be ordered as the corrosion reaction proceeded. Yang et al. [11] studied the effect of common phosphate-containing alkaline-solution contamination in sewage on the mechanical properties of laterite and found that the cohesive force of the contaminated laterite decreased, the internal friction angle decreased, and the compressibility increased. Based on the images of the microstructure, it was confirmed that the weakening of the microstructure was the cause of the change of the engineering properties. Zhang [12] conducted a consolidated quick-shear test on alkaline-contaminated soil and pointed out that, after corrosion by an alkaline solution, the cohesive force of the soil was greater than that of uncorroded soil, but the internal friction angle decreased after corrosion. Liu and $\mathrm{Li}[13]$ analyzed the influence of wetting-drying cycles on the shear strength of laterite under different $\mathrm{pH}$ conditions. The results showed that when the number of wetting-drying cycles was constant, with increasing concentration of the alkaline solution, the cohesive force of laterite decreased, and the internal friction angle increased when the alkalinity of the solution increased. In summary, the existing research results generally showed that, during the corrosion by alkaline solutions, the permeability coefficient of laterite increases, the strength decreases, and the engineering properties of the soil generally show a deteriorating trend. Cuisinier [14] studied soil mixed with lime and found that the lime improved the soil's mechanical properties. Sunil et al. [15] studied the influence of landfill leachate on the properties of laterite, and the results showed that, after leachate erosion, the liquid limit and plasticity index of the laterite increased, the cohesion of the laterite increased, the internal friction angle decreased, and the clay content increased. Yang et al. [16] studied the strength of soil-cement after acid and alkali erosion and suggested that an acidic environment had a greater impact on the strength of the soilcement than an alkaline environment. Gualtieri et al. [17] found that acid and alkali erosion affected the microstructure and chemical composition of laterite.

Researchers have explained the mechanism and reasons for the influence of alkaline solutions on laterite from different aspects. First, according to colloidal-chemistry-related theories $[18,19]$, when the laterite is in water $(\mathrm{pH}$ value of about 7), the surfaces of clay minerals are negatively charged, and the surfaces of free iron oxide in laterite is positively charged. Due to the attraction of the electric charges, the strength of the soil is stable. In an alkaline liquid, the clay minerals and free iron oxide are negatively charged at the same time, which results in a repulsive effect, thereby reducing the strength of the laterite. Second, $\mathrm{SiO}_{2}$ and $\mathrm{Al}_{2} \mathrm{O}_{3}$ in laterite can undergo chemical reactions with an alkaline solution, and the change in the chemical composition of the soil during the reaction is the cause of the change in the physical and mechanical properties of the soil [7-9, 11]. Third, the ion exchange of free iron oxide in laterite weakens the bonding effect between particles, resulting in changes in the soil engineering properties $[5,20]$.

In terms of the test methods for the influence of chemical solution corrosion on the physical and mechanical properties of laterite, due to cost limitations, the immersion and mixing methods are mostly used for sample treatment. In the immersion method, the soil is immersed in a chemical solution, and the changes in the physical and mechanical properties of the soil before and after immersion are studied by changing the immersion time, solution concentration, and original state of the soil. In the mixing method, chemical solutions of different concentrations are used to replace pure water when the remolded samples are prepared, and the curing concentration is changed to study the changes in the physical and mechanical properties of the soil before and after the introduction of chemical solutions. These different test methods lead to different conclusions. Although these two methods can reflect the conditions for some projects, for water retaining dams, tailings dams, and other projects, the water inside the soil is in a slow-flowing state and has been subjected to permeation and corrosion by chemical solutions for long periods. Therefore, the immersion and mixing methods cannot reflect the actual conditions in such projects. It is also important to develop a sample processing method that can reflect the actual engineering requirements and ensure the reliability of the research conclusions.

In this paper, a device for long-term permeation with a chemical solution was constructed for triaxial specimens, and the macromechanical properties of laterite after being corroded by alkaline-solution permeation under different concentrations and different cycles were studied; in combination with the chemical composition and microstructure analysis, the reasons for the permeation corrosion were discussed.

\section{Experimental Procedure}

2.1. Modification of Permeameter. Currently, there are commercial permeameters, but their materials are generally copper or steel. Thus, chemical solutions have a corrosive effect on them, which has a great impact on the research 
conclusions. The specimen sizes of the existing permeameters are not suitable for triaxial shear test, and the triaxial shear tests cannot be performed after a permeation test. Therefore, a device was designed and constructed for long-term permeation using chemical solutions that were suitable for the triaxial samples in this work. Plexiglass resistant to acid and alkali corrosion was selected as the material, and the size of the sample chamber was the same as that of the triaxial sample, which avoided the impact of secondary cutting on the sample. The modified permeameter is shown in Figure 1.

2.2. Test Materials. The laterite samples were collected from a construction site in Dongxiang County, Jiangxi Province, with a sampling depth of $3 \mathrm{~m}$, which was often used as dam filling material. The soil sample was a brick-red color, with a natural dry density of $1.47 \mathrm{~g} / \mathrm{cm}^{3}$. The physical and chemical properties of the soil sample are shown in Table 1. After the soil sample was passed through a $0.5 \mathrm{~mm}$ sieve, it was compacted into a standard triaxial sample using the modified permeameter. The initial dry density of the soil was $1.55 \mathrm{~g} / \mathrm{cm}^{3}$, and the degree of compaction was $96 \% . \mathrm{NaOH}$ solution is easy to obtain but not easy to volatilize, which was selected as the alkaline solutions for the corrosion tests. Pure water was used to prepare the solutions with concentrations of $0.04,0.4,1,2$, and $4 \mathrm{~g} / \mathrm{L}$ with corresponding $\mathrm{pH}$ values of $11.0,12.0,12.4,12.7$, and 13.0, respectively. During the test, the alkali concentration was checked every 24 hours.

\subsection{Test Procedure}

(1) Test of Mechanical Properties of Laterite under Alkaline-Solution Corrosion Conditions. The samples were permeated and corroded by the alkaline solutions described above. Permeation tests were carried out, and samples were removed for analysis on Day $30,90,150,210$, and 300 . The SLB-1 stress-strain controlled triaxial test apparatus was used to carry out triaxial consolidated drained shear tests. The test confining pressures were selected as 100,200 , and $300 \mathrm{kPa}$, respectively.

(2) Chemical Composition and Particle Analysis Tests of Laterite. The chemical compositions and particle contents of the laterite samples after the alkalinesolution permeation and triaxial test were determined. Before the test, the three samples under the same permeation time and alkali concentration conditions were kneaded, crushed, and mixed. The average values of duplicate tests were reported in this paper.

(3) Microstructure Test of Soil Samples. The microstructures of representative samples with different alkaline-solution concentrations and different permeation times were examined using SEM, and the microstructural changes of the soil samples after alkaline-solution corrosion were analyzed.

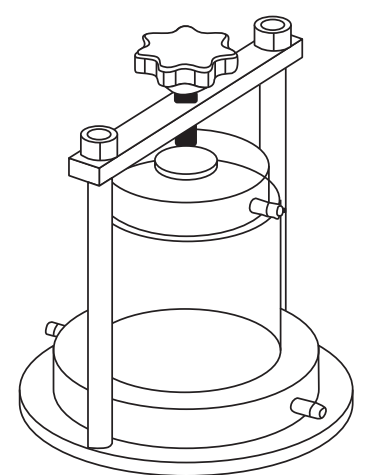

Figure 1: Modified permeameter.

TABle 1: Physical and chemical properties of soil samples.

\begin{tabular}{lcc}
\hline Property & Result \\
\hline Particle specific gravity & & 2.70 \\
Liquid limit water content (\%) & 46.5 \\
Plastic limit water content (\%) & & 22.3 \\
Maximum dry density $\left(\mathrm{g} / \mathrm{cm}^{3}\right)$ & & 1.61 \\
Optimum water content (\%) & & 21.3 \\
& $>0.075$ & 12.2 \\
Particle composition (\%) & $0.075-0.005$ & 55.0 \\
& $<0.005$ & 32.8 \\
$\mathrm{Fe}_{2} \mathrm{O}_{3}$ content (\%) & & 8.5 \\
$\mathrm{Al}_{2} \mathrm{O}_{3}$ content (\%) & 17.6 \\
$\mathrm{SiO}_{2}$ content $(\%)$ & & 67.3 \\
\hline
\end{tabular}

\section{Influence of Permeation Effect of Alkaline Solution on Mechanical Properties of Laterite}

3.1. Changes in $c$ and $\varphi$ Values with Permeation Time and Alkaline Solution Concentration. Based on the results of the triaxial test, the curves of the cohesive force $c$ and the internal friction angle $\varphi$ were plotted as functions of the permeation time and alkaline-solution concentration.

Figure 2 shows the variations in the strength parameters $c$ and $\varphi$ with the permeation time for different concentrations of the alkaline solutions. The test results showed that, for the $\mathrm{pH}$ values used in the alkaline-solution permeation tests, the strength parameters $c$ and $\varphi$ all decreased with increasing permeation time. At the same time, there were also differences in the pattern of decline in the strength parameters $c$ and $\varphi$ for the different concentrations of the alkaline solutions. When the permeation time was $30-90 \mathrm{~d}$ and the $\mathrm{pH}$ value was 11 or 12 , the changes in the strength parameters $c$ and $\varphi$ were relatively small. When the permeation time was $30-90 \mathrm{~d}$ and the $\mathrm{pH}$ value was 13 , the strength parameters $c$ and $\varphi$ decreased significantly. When the $\mathrm{pH}$ was 13 , the strength parameters $c$ and $\varphi$ changed considerably in the early stage of permeation (30-90 d), but they gradually tended to stable values with increasing permeation time, indicating that the strength parameters $c$ and $\varphi$ could not decrease indefinitely with increasing permeation time.

Figure 3 shows the variations in the strength parameters $c$ and $\varphi$ with the concentration of the alkaline solution after 


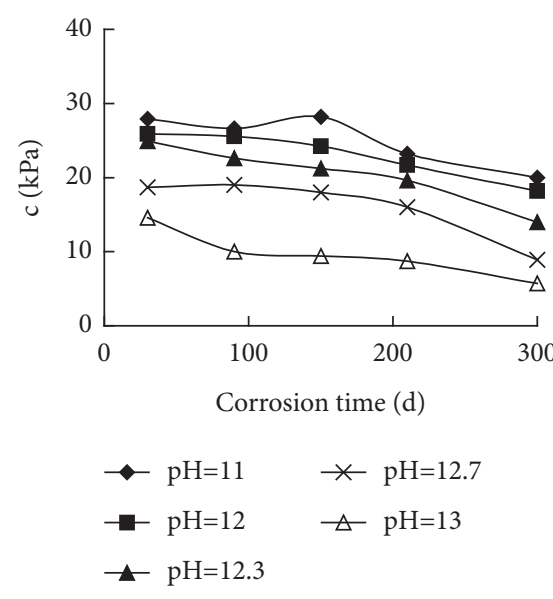

(a)

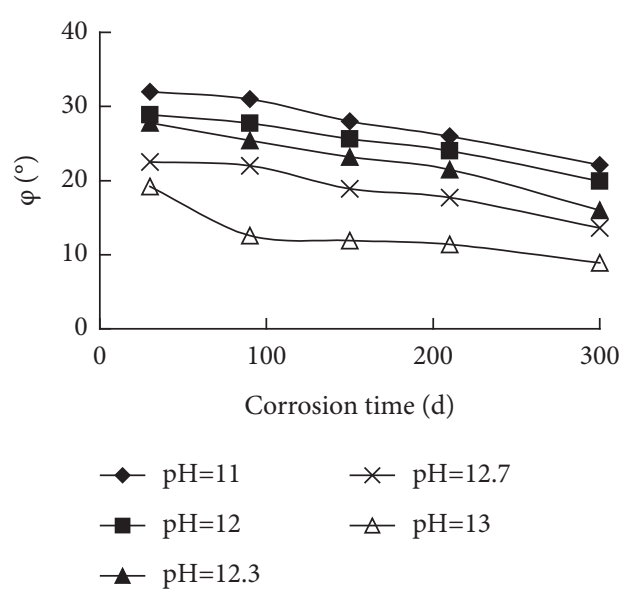

(b)

FIGURE 2: Variation patterns of the strength parameters with the permeation time at different alkaline-solution concentrations. (a) $c$ and (b) $\varphi$.

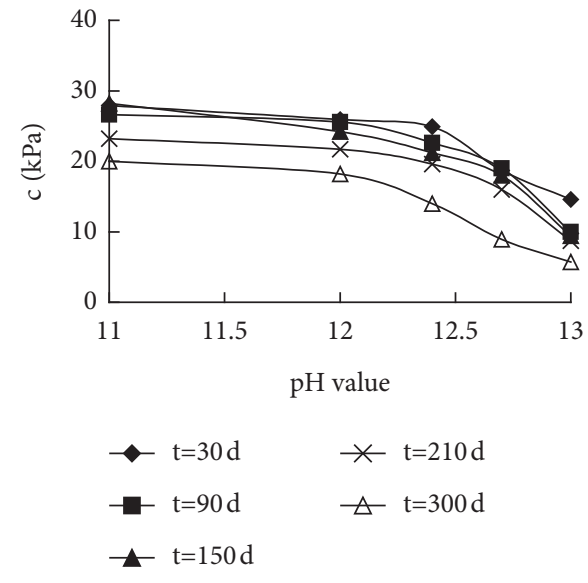

(a)

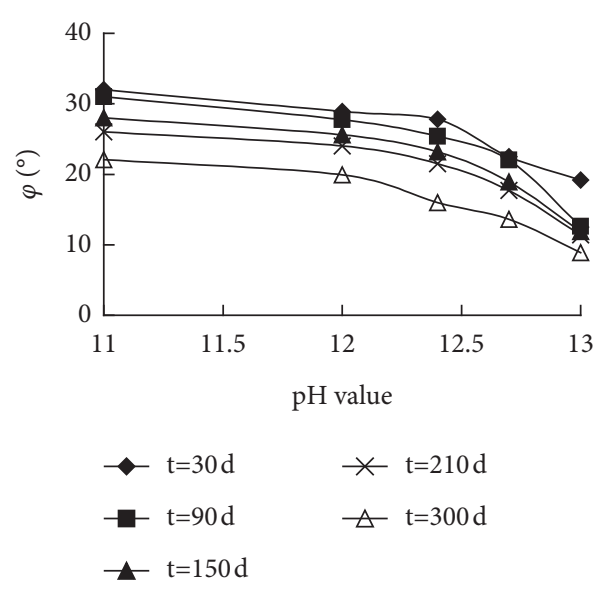

(b)

FIGURE 3: Variation patterns of the strength parameters with the alkaline-solution concentration after different permeation times. (a) $c$ and (b) $\varphi$.

different permeation times. Under different permeation conditions, the strength parameters $c$ and $\varphi$ all decreased with increasing concentration of the alkaline solution. Furthermore, regardless of the duration of the permeation by the alkaline solution, when the alkaline solution $\mathrm{pH}$ was less than 12, the strength parameters $c$ and $\varphi$ of the laterite changed slightly. When the concentration of the alkaline solution was greater than 12 , the strength parameters $c$ and $\varphi$ of the laterite decreased considerably with increasing concentration of the alkaline solution.

Laterite is acidic. Due to the presence of the alkaline solution, the $\mathrm{pH}$ value of the laterite increased, causing the nearby free iron oxide and alumina to become negatively charged, which repelled the clay minerals with the same electric charge, resulting in a decrease in the connecting capability of the particles. As the permeation time increased, this led to a decrease in the strength parameters of the laterite. With increasing $\mathrm{pH}$ value, the connecting capability between the particles decreased more significantly, which caused the strength parameters of the laterite to decrease with increasing concentration of the alkaline solution at different permeation times.

\subsection{Influence of Alkaline-Solution Concentration and Per-} meation Time on $K, n$, and $R_{f}$. Similarly, based on the results of the triaxial test, the $K, n$, and $R_{f}$ values in the DuncanChang model were determined and are summarized in Table 2.

The variations in $K, n$, and $R_{f}$ with the permeation time under different alkaline-solution concentrations were plotted, as shown in Figures 4-6.

$K$ reflects the value of $E_{i}$ under a confining pressure $\sigma_{3}=100 \mathrm{kPa}$. Figure 4 shows that, at the test concentration, $K$ decreased with increasing corrosion time, indicating that the same stress could cause greater strain after corrosion. The reasons for this phenomenon were as follows. First, due to permeation effect, the alkaline solution reacted with the chemical substances that constituted the soil particles, and the new chemical substances were removed by the 
TABLE 2: $K, n$, and $R_{f}$ values of laterite at different alkaline-solution concentrations and permeation times.

\begin{tabular}{lcccc}
\hline $\mathrm{pH}$ & Time $(\mathrm{d})$ & $K(\mathrm{kPa})$ & $n$ & $R_{f}$ \\
\hline 11 & 30 & 639.24 & 0.719 & 0.97 \\
11 & 90 & 549.26 & 0.705 & 0.98 \\
11 & 150 & 460.37 & 0.746 & 1.00 \\
11 & 210 & 331.59 & 0.739 & 0.97 \\
11 & 300 & 276.56 & 0.718 & 1.01 \\
12 & 30 & 516.89 & 0.758 & 0.97 \\
12 & 90 & 396.88 & 0.718 & 0.98 \\
12 & 150 & 327.42 & 0.684 & 0.98 \\
12 & 210 & 190.32 & 0.743 & 1.00 \\
12 & 300 & 169.25 & 0.747 & 0.86 \\
12.4 & 30 & 369.07 & 0.754 & 1.00 \\
12.4 & 90 & 293.23 & 0.724 & 1.00 \\
12.4 & 150 & 220.51 & 0.750 & 0.97 \\
12.4 & 210 & 165.94 & 0.728 & 1.00 \\
12.4 & 300 & 139.83 & 0.742 & 1.00 \\
12.7 & 30 & 237.52 & 0.747 & 0.99 \\
12.7 & 90 & 214.79 & 0.718 & 0.99 \\
12.7 & 150 & 173.47 & 0.725 & 0.99 \\
12.7 & 210 & 135.84 & 0.786 & 1.01 \\
12.7 & 300 & 128.79 & 0.714 & 0.99 \\
13 & 30 & 199.18 & 0.745 & 1.00 \\
13 & 90 & 153.28 & 0.741 & 0.99 \\
13 & 150 & 113.36 & 0.842 & 0.97 \\
13 & 210 & 65.78 & 0.724 & 0.97 \\
13 & 300 & 66.51 & 0.725 & 0.96 \\
\hline & & & &
\end{tabular}

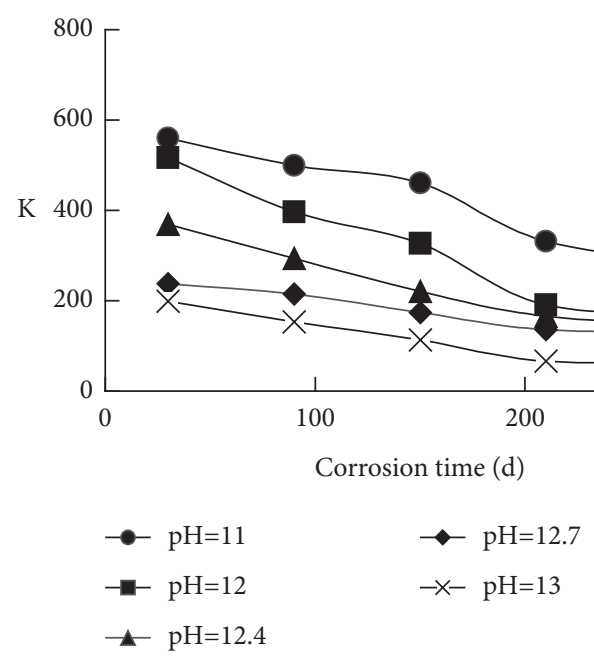

FIGURE 4: Variation pattern of the parameter $K$ with the permeation time at different alkaline-solution concentrations.

permeation effect, thereby increasing the sizes of the voids between the particles. Under the action of the axial stress, a relatively large compression deformation was produced in the void. Second, due to the chemical action of the alkaline solution, the repulsive forces between the particles and between the particle groups were reduced, and the voids are formed more easily under the action of the axial stress. Thus, a relatively large deformation was produced under the same stress.

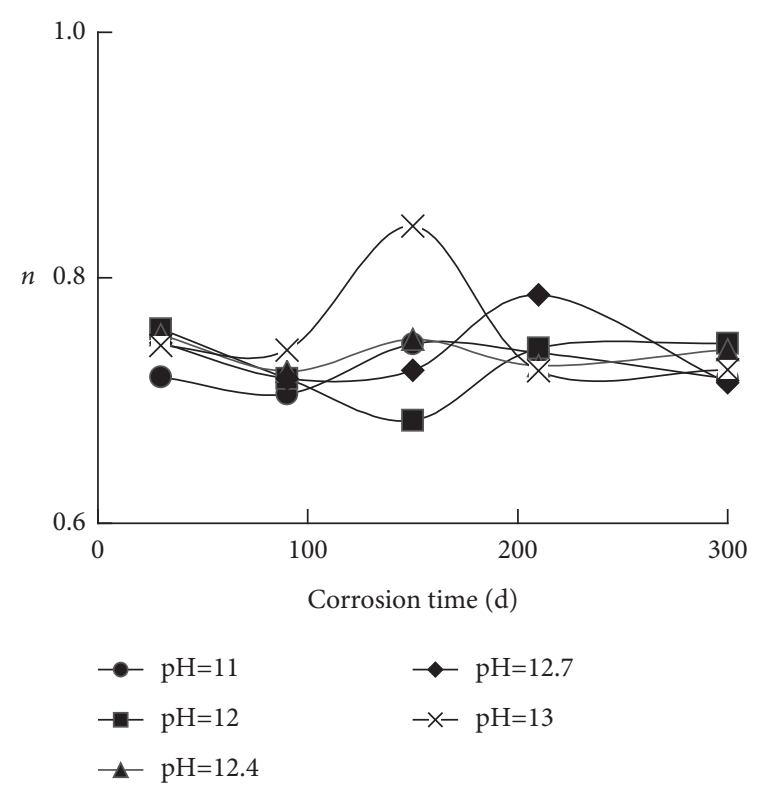

FIGURE 5: Variation pattern of the parameter $n$ with the permeation time at different alkaline-solution concentrations.

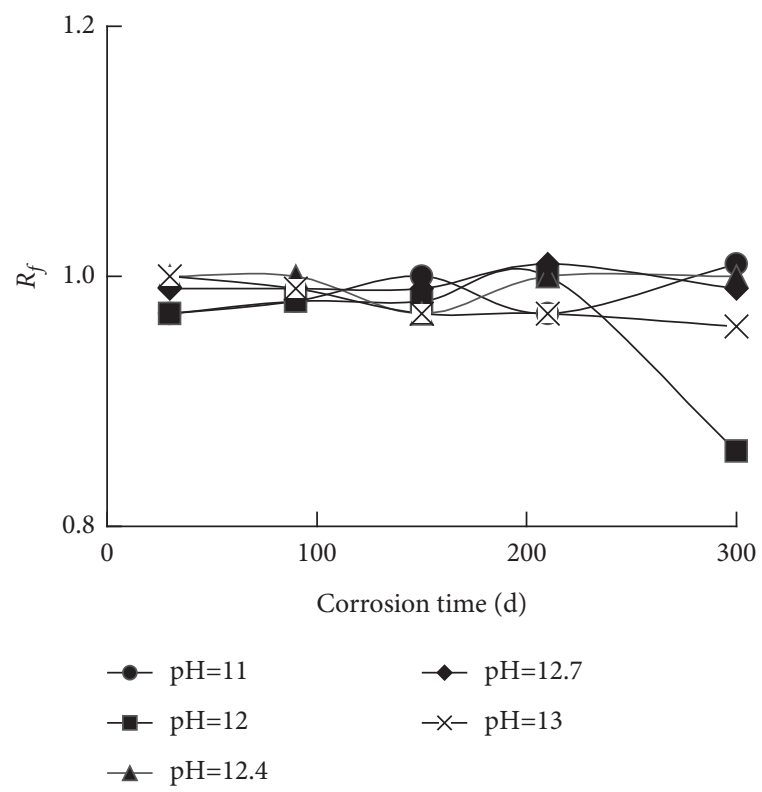

Figure 6: Variation pattern of the parameter $R_{f}$ with the permeation time at different alkaline-solution concentrations.

$n$ reflects the increasing trend of $E_{i}$ under different confining pressures $\sigma_{3}$. The larger $n$ was, the greater its impact on $E_{i}$ became. The experimental results showed that changes in $n$ showed no evident pattern with the alkalinesolution concentration and permeation time. The maximum value was 0.842 , the minimum value was 0.684 , the median was 0.739 , and the average value was 0.738 .

$R_{f}$ represents the ratio of the strength value of the peak point (or $\varepsilon_{1}=15 \%$ ) in the stress-strain curve to the maximum deviator stress difference. In practical applications, the maximum deviator stress difference is derived from the 
relationship $\varepsilon_{1} /\left(\sigma_{1}-\sigma_{3}\right) \sim \varepsilon_{1}$. The experimental results showed that changes in $R_{f}$ exhibited no evident pattern with the variations in the alkaline-solution concentration and permeation time. The maximum value was 1.00 , the minimum value was 0.86 , the median was 0.99 , and the average value was 0.98 .

\subsection{Quantitative Expression of Influence of Alkaline-Solution} Concentration and Permeation Time on Model Parameters. The above results showed that no variation patterns were evident in the relationships of $n$ and $R_{f}$ with the alkalinesolution concentration and permeation time. In contrast, $c, \varphi$, and $K$ showed regular changes with changes in the alkalinesolution concentration and permeation time. The influence of the alkaline-solution $\mathrm{pH}$ and permeation time $t$ on $c, \varphi$, and $K$ can be quantitatively expressed in a general form as follows:

$$
\left\{\begin{array}{l}
c \\
\phi \\
K
\end{array}\right\}=f(\mathrm{pH}, t)
$$

For a specific alkaline-solution concentration condition, the influence of the permeation time on $c, \varphi$, and $K$ can be quantitatively expressed as follows:

$$
\left\{\begin{array}{l}
c \\
\phi \\
K
\end{array}\right\}=f(t) .
$$

With the cohesive force $c$ as an example, the power function, exponential function, logarithmic function, and linear function were used for fitting. When the $\mathrm{pH}$ of the alkaline solution was 11 , it was found that the linear function could efficiently express the influence of the permeation time on $c$ and $\varphi$. The cohesive force after different permeation times could be expressed as follows:

$$
c=-0.0298 t+29.832 \text {. }
$$

The internal friction angle at different permeation times could be expressed as follows:

$$
\varphi=-0.03779 t+33.71475 \text {. }
$$

The influence of the corrosion time on $K$ could be expressed by an exponential function as follows:

$$
K=633.21 e^{-0.003 t} \text {. }
$$

It should be pointed out that the conclusion of formulae (3)-(5) was based on 300 days of erosion data. When the erosion time increases, $c, \varphi$, and $K$ will not decrease indefinitely.

\section{Mechanism of Influence of Alkaline-Solution Permeation on Mechanical Properties of Laterite}

To explore the reasons for the influence of the alkalinesolution permeation on the mechanical properties of laterite, the chemical composition, particle composition, and microstructure of laterite were determined using the soil samples after triaxial tests.

\subsection{Influence of Alkaline-Solution Permeation on Chemical} Composition of Laterite. The main chemical elements, $\mathrm{SiO}_{2}$, $\mathrm{Fe}_{2} \mathrm{O}_{3}$, and $\mathrm{Al}_{2} \mathrm{O}_{3}$, of the laterite after the triaxial test were measured, and the results showed that the effects of the permeation action of the alkaline solution on the three components were different.

Figure 7 and 8 show that, at a fixed alkaline-solution concentration, the contents of $\mathrm{Fe}_{2} \mathrm{O}_{3}$ and $\mathrm{Al}_{2} \mathrm{O}_{3}$ in the laterite exhibited fluctuating and decreasing trends with increasing corrosion time. At the same corrosion time, the contents of both $\mathrm{Fe}_{2} \mathrm{O}_{3}$ and $\mathrm{Al}_{2} \mathrm{O}_{3}$ gradually decreased with increasing alkaline-solution concentration. In general, the $\mathrm{Fe}_{2} \mathrm{O}_{3}$ content varied from $7.19 \%$ to $5.59 \%$, and the range of variation was only $1.6 \%$. The $\mathrm{Al}_{2} \mathrm{O}_{3}$ content varied from $16.7 \%$ to $15.0 \%$, and the range of variation was $1.7 \%$. The low values of the two components appeared in the laterite samples that were corroded with relatively high concentrations of the alkaline solution for a long time.

In Figure 9, the test results showed that, at a fixed alkaline-solution concentration, the $\mathrm{SiO}_{2}$ content in the laterite did not show an evident trend with the increase in the alkaline-solution concentration or the corrosion time. The overall change was between $65.9 \%$ and $63.5 \%$, corresponding to a range of $2.4 \%$.

The above test results showed that the alkaline-solution permeation had an impact on the $\mathrm{Fe}_{2} \mathrm{O}_{3}$ and $\mathrm{Al}_{2} \mathrm{O}_{3}$ of the laterite. $\mathrm{Fe}_{2} \mathrm{O}_{3}$ and $\mathrm{Al}_{2} \mathrm{O}_{3}$ are important sesquioxides that constitute laterite. They are very important for the particle composition of laterite and play a role in the aggregation and bonding. When the soil environment changes, sesquioxides will respond, and the engineering properties of laterite will change.

\subsection{Influence of Alkaline-Solution Permeation on Composi-} tion of Laterite Particles. The particle contents of the laterite samples after the alkaline-solution permeation and triaxial tests were measured. Before the measurements, three samples under the same permeation time and alkaline-solution concentration conditions were kneaded, crushed, and mixed. The measurement of the soil particle content was carried out according to the requirements of the "Geotechnical Test Regulations" (SL237-1999). The average values of duplicate measurements are reported in this paper.

The measurement results showed that when the $\mathrm{pH}$ of the alkaline solution was 12.7 or 13 , the content of particles larger than $0.075 \mathrm{~mm}$ was $14.7-15.4 \%$. Upon increasing the alkalinesolution concentration, this content gradually decreased to $12.8-14.7 \%$, indicating that, during the process of permeation with alkaline solutions at relatively high concentrations, some of the coarse particles were gradually broken or decomposed and transformed into smaller particles.

The patterns of change in the clay particle $(<0.005 \mathrm{~mm})$ content of laterite at different permeation times and alkalinesolution concentrations were plotted. Figure 10(a) shows the 


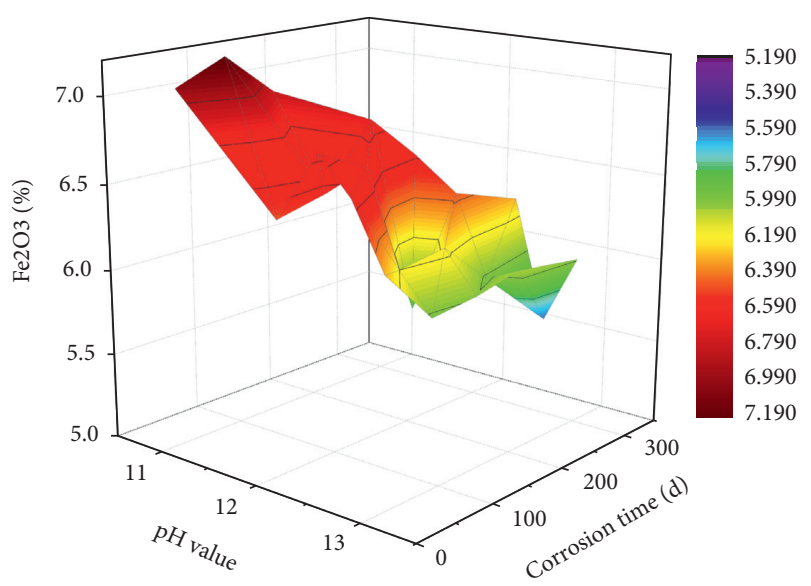

Figure 7: Changes of the $\mathrm{Fe}_{2} \mathrm{O}_{3}$ content in the laterite at different alkaline-solution concentrations and permeation times.

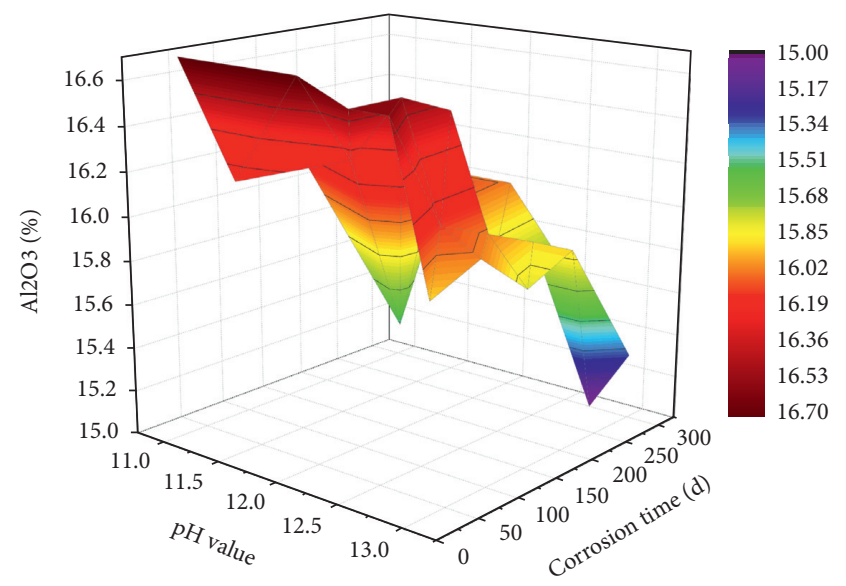

FIgURE 8: Changes of the $\mathrm{Al}_{2} \mathrm{O}_{3}$ content in the laterite at different alkaline-solution concentrations and permeation times.

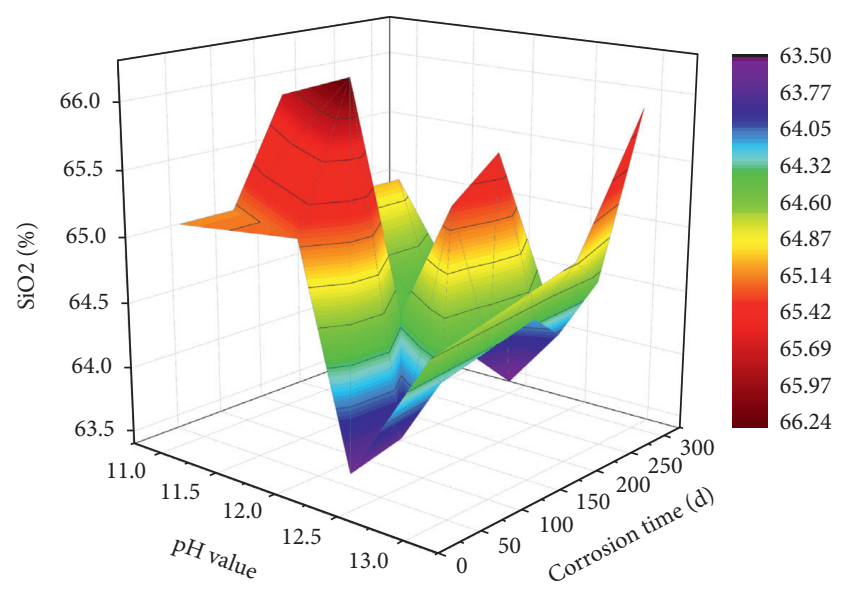

Figure 9: Changes of the $\mathrm{SiO}_{2}$ content in the laterite at different alkaline-solution concentrations and permeation times.

correlation between the clay content and permeation time during alkaline-solution permeation at different concentrations. The content of clay particles was generally positively correlated with the permeation time. That is, under the corrosion during the alkaline-solution permeation, the content of clay particles increased with increasing time, indicating that the alkaline solution had a decomposition effect on the particles in the laterite and could decompose large particles into small particles, resulting in an increase in the content of clay particles. The increase in the clay content was different under the permeation action of different concentrations of alkaline solution. When the concentration was low $(\mathrm{pH}=11)$, the clay particle content basically increased linearly with the permeation time. With increasing concentration of the alkaline solution, the clay particle content first increased rapidly with increasing time, and then, the magnitude of the increase gradually decreased. When the concentration was relatively high $(\mathrm{pH}=13)$, the clay particle content reached a high level initially, and then, it slowly increased and stabilized. Under different alkaline-solution concentrations, the clay particle content could not increase constantly with increasing time, and there was a maximum value. In this study, the highest value was $63 \%$.

Figure 10(b) shows the correlation between the content of clay particles and the permeation time. Due to the corrosion during alkaline-solution permeation, the content of clay particles increased with increasing corrosion time. The increase in the clay content was also different under the permeation effect of alkaline solutions at different concentrations. When the permeation time was short $(30 \mathrm{~d})$, the clay content increased rapidly with increasing alkaline concentration. However, when the permeation time was relatively long, the clay particle content increased slowly with increasing concentration of the alkaline solution.

4.3. Influence of Alkaline-Solution Permeation on Soil Microstructure. Using SEM, the microstructure of the laterite was observed, and images were captured. The changes in the microstructure before and after alkaline-solution permeation were qualitatively analyzed.

\subsubsection{Mesoscopic Overall Characteristics of Soil before and} after Alkaline-Solution Permeation. The typical mesostructure of the soil body was studied under a magnification of 50x. As shown in Figure 11, large-particle structures were present in the laterite without alkaline-solution permeation. The particle diameter was $1-2 \mathrm{~mm}$, and there were large voids between the particles. As shown in Figure 12, after long-term permeation with the alkaline solution at a relatively high concentration, the soil particles became smaller and more ordered, and the voids between the soil particles could no longer be observed under low-magnification conditions.

4.3.2. Changes in Soil Microstructure after Alkaline-Solution Permeation. After the laterite was permeated by the alkaline solution, the microstructural characteristics of the soil surface were photographed, and characteristic images were obtained at a magnification of 10,000x. 


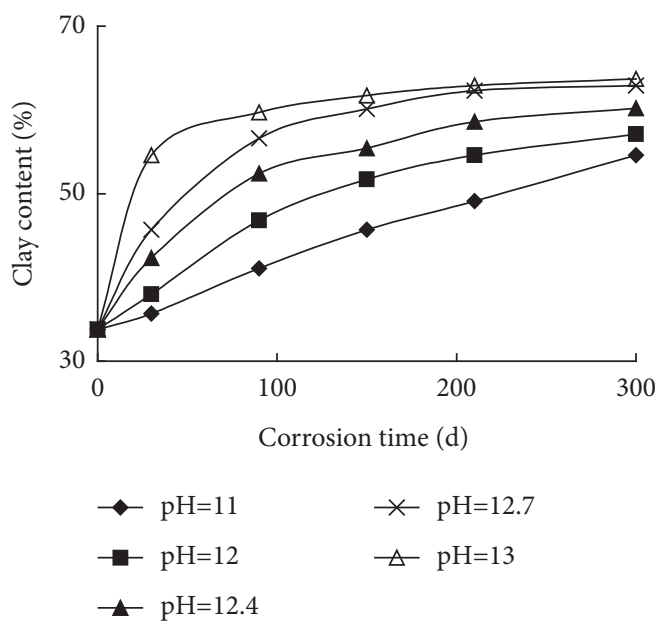

(a)

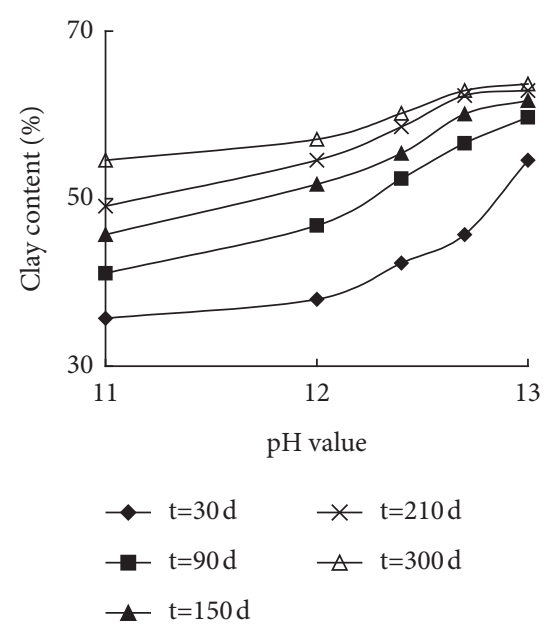

(b)

Figure 10: Variation in the clay particle content.

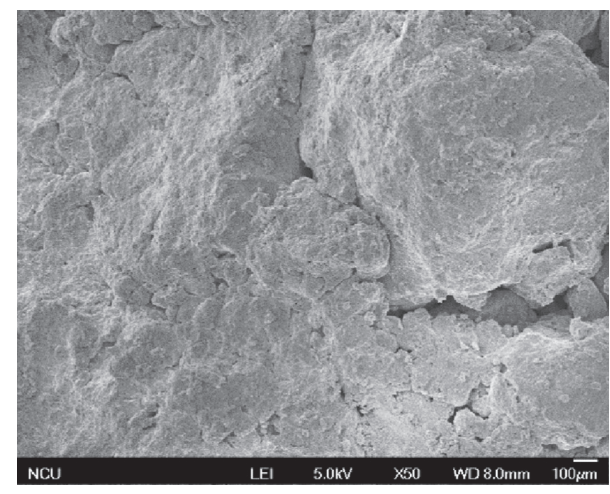

Figure 11: Mesostructure of the laterite without alkaline-solution permeation.

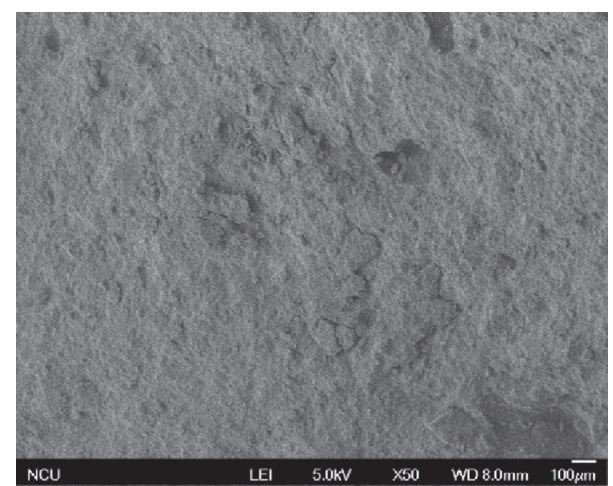

Figure 12: Mesostructure of the laterite after alkaline-solution permeation $(\mathrm{pH}=13$ and $t=210 \mathrm{~d})$.

As shown in Figure 13(a), the particle composition of the soil could not be observed clearly at a magnification of $10,000 \mathrm{x}$ when a low-concentration alkaline solution was used and the permeation corrosion was in the early stage. Furthermore, the pores between the soil particles were not visible. When the concentration of the alkaline solution increased and the permeation corrosion effect developed to a certain extent (Figure 13(b)), the number of small soil particles and the number of pores between the particles increased, and the particle sizes of the soil particles were mostly $1-3 \mu \mathrm{m}$. The above findings revealed that, with increasing alkaline-solution concentration and permeation time, large particles in the soil were gradually broken and decomposed into small particles.

4.4. Analysis of Cause of Influence of Alkaline-Solution Permeation on Mechanical Properties of Laterite. Based on the analysis of the chemical composition, particle composition, and microstructure of laterite, we propose that the corrosion of laterite by $\mathrm{NaOH}$ alkaline solutions can be divided into three stages.

In the first stage, the contents of $\mathrm{Fe}_{2} \mathrm{O}_{3}$ and $\mathrm{Al}_{2} \mathrm{O}_{3}$ components in the laterite remained unchanged or decreased slightly, the particle composition of the laterite did not change considerably, the microstructure tended to be ordered, and the strength of the laterite was reduced. These phenomena mainly occurred because the $\mathrm{pH}$ value of the external environment increased, and the bonding capability between the soil particles was weakened. This stage occurred in laterite samples with relatively short alkaline-solution corrosion times.

In the second stage, the contents of $\mathrm{Fe}_{2} \mathrm{O}_{3}$ and $\mathrm{Al}_{2} \mathrm{O}_{3}$ components in the laterite were reduced, the content of clay particles in the laterite increased, the microstructure tended to be ordered, and the strength of the laterite continued to decrease. These phenomena occurred because the internal connecting strength of the large particles was weakened, and some large particles decomposed into smaller particles. This stage occurred in the laterite samples that were corroded by low-concentration alkaline solutions for a long time.

In the third stage, the clay particle content in the laterite was stable or slightly increased, the microstructure was ordered, and the strength of the laterite during the corrosion by an alkaline solution at a relatively high concentration 


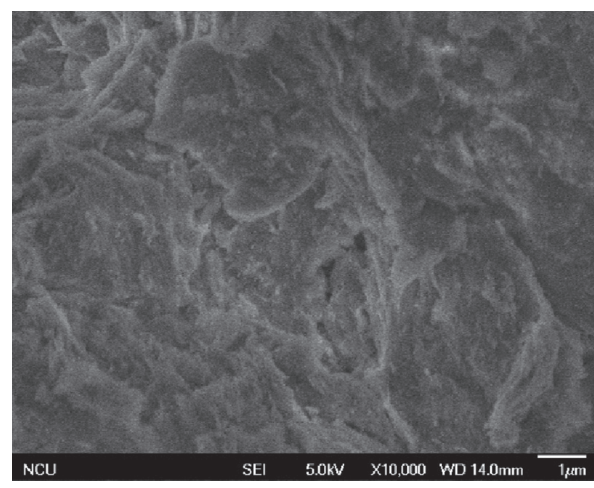

(a)

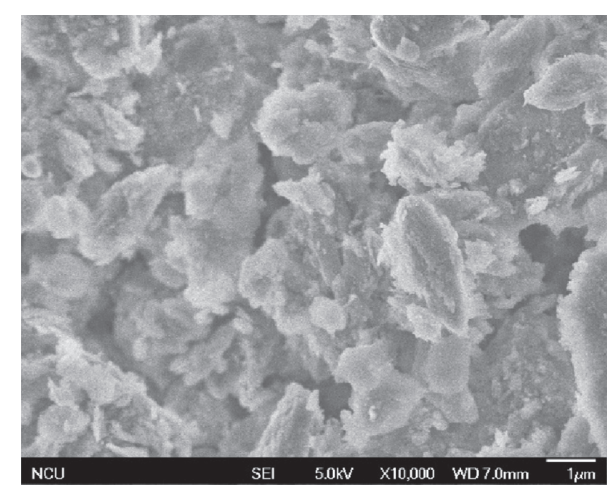

(b)

FIgURE 13: Microstructure of the laterite after alkaline-solution permeation: (a) $\mathrm{pH}=11, t=30 \mathrm{~d}$ and (b) $\mathrm{pH}=13, t=210 \mathrm{~d}$.

tended to be stable. The reason for these phenomena was that, under the long-term corrosion by the alkaline solution, the large particles in the laterite gradually decomposed into particles that were sufficiently small, resulting in a stable state in the laterite.

In general, when laterite is slowly corroded by an alkaline solution, such as $\mathrm{NaOH}$, and the environment in the laterite changes, the bonding effect of $\mathrm{Al}_{2} \mathrm{O}_{3}, \mathrm{Fe}_{2} \mathrm{O}_{3}$, and other sesquioxides in the laterite to the laterite particles is weakened. At the same time, the effective chemical components $\mathrm{Al}_{2} \mathrm{O}_{3}$ and $\mathrm{Fe}_{2} \mathrm{O}_{3}$ are converted into soluble or slightly water-soluble powdery nonsticky substances, which flow out of the soil with pressurized seepage water. Along with the change in the chemical composition, the outflow of the substances, and the reduction of the bonding effect of the laterite particles, the physical properties of the laterite change. Under certain external conditions, the chemical and particle compositions of the laterite determine its mechanical properties. During the slow corrosion using an alkaline solution, the $\mathrm{Al}_{2} \mathrm{O}_{3}$ and $\mathrm{Fe}_{2} \mathrm{O}_{3}$ in the laterite are gradually leached, the connection between the soil particles is gradually weakened, the large particles are transformed into small particles, and some small particles flow out of the soil via permeation. The weakening of the connection between the particles and the loss of small particles lead to significant changes in the mechanical properties of the laterite.

In summary, the damage process of laterite by alkaline solutions can be described simply as follows: the alkalinesolution permeation changes the chemical composition of laterite and the connecting strength of the soil particles, which leads to changes in its physical and mechanical properties.

\section{Conclusions}

(1) After laterite was corroded by alkaline-solution permeation, the strength parameters $c, \varphi$, and $K$ all decreased with increasing corrosion time and alkaline-solution concentration. The alkaline-solution corrosion had a minor effect on the strength parameters $n$ and $R_{f}$. Through the quantitative analysis of the parameters of the Duncan-Chang model, a quantitative expression of the laterite $\left(E_{t}\right)$ at $\mathrm{pH}=11$ after different permeation times was deduced.

(2) The study showed that the contents of $\mathrm{Al}_{2} \mathrm{O}_{3}$ and $\mathrm{Fe}_{2} \mathrm{O}_{3}$ fluctuated and decreased with increasing alkaline-solution concentration and corrosion time. The overall variation ranges were relatively small. In general, low contents appeared in the laterite samples that were corroded by a relatively high concentration of the alkaline solution for a long time. The $\mathrm{SiO}_{2}$ content exhibited no evident relationship with increasing alkaline-solution concentration and corrosion time. Overall, the content of clay particles and the permeation time were positively correlated with the concentration of the alkaline solution. The laterite without alkaline-solution permeation possessed a large-particle structure, and there were large voids between the particles. After the alkaline-solution permeation, the soil particles became smaller and were arranged in an ordered state.

(3) The corrosion process of the alkaline solution on the laterite was summarized. It was proposed that the corrosion of laterite by an alkaline solution, such as $\mathrm{NaOH}$, can be divided into three stages. The permeation effect of the alkaline solution changed the chemical composition of laterite and the connecting strength of soil particles, leading to the changes in its physical characteristics and mechanical properties.

\section{Data Availability}

The data used to support the findings of this study are available from the corresponding author upon request.

\section{Conflicts of Interest}

The authors declare that they have no conflicts of interest.

\section{Acknowledgments}

This work was supported by the National Key R\&D Program of China (no. 2017YFC1502604) and Hydraulic Science Foundation of Jiangxi Province (KT201608 and 201921YBKT03). 


\section{References}

[1] J.-W. Gu, "Influence of acid and alkali waste on soil foundation and soil engineering quality," Chinese Journal of Geotechnical Engineering, vol. 10, no. 4, pp. 72-78, 1988, in Chinese.

[2] Q. Li, B. Shi, and Y.-C. Wang, "Environmental geotechnical properties of soil contained by waste alkaline liqour from paper mills," Environment Pollution and Control, vol. 19, no. 5 , pp. 16-18, 1999, in Chinese.

[3] C.-P. Zhu, H.-L. Liu, and Y. Shen, "Laboratory tests on shear strength properties of soil polluted by acid and alkali," Chinese Journal of Geotechnical Engineering, vol. 33, no. 7, pp. 1146-1152, 2011, in Chinese.

[4] H.-L. Liu, C.-p. Zhu, and X.-L. Zhang, "Fundamental physical properties of soil polluted by acid and alkali in laboratory," Chinese Journal of Geotechnical Engineering, vol. 30, no. 8, pp. 1213-1217, 2008, in Chinese.

[5] R. Chen, Study on Deterioration of Hydraulic Characteristics of Red Earth Dam foundation, Kunming University of Science and Technology, Kunming, China, 2010, in Chinese.

[6] J.-Y. Li, Experimental Study on Failure Mechanism of Red Earth Dam by Alkaline materials, Kunming University of science and technology, Kunming, China, 2012, in Chinese.

[7] H.-S. Yang, Y. Yu-Lu, W. Hai, H. Ying-Ting, W. Hao, and W. Yi, "Eroding and imperiling of alkaline materials in laterite structure," Hydrogeology \& Engineering Geology, vol. 39, no. 5, pp. 64-68, 2012, in Chinese.

[8] H.-S. Yang, Y. Yu-Lu, Y. Yi-Zhi et al., "Chemical erosion of laterite soils by alkaline materials," Journal of Building $\mathrm{Ma}$ terials, vol. 16, no. 1, pp. 159-163, 2013, in Chinese.

[9] H.-S. Yang, W. Hai, Y. Yang, L. Jin-Yu, and Y. Xiao-Lin, "Deterioration reaction between alkali materials and laterite dams," Chinese Journal of Geotechnical Engineering, vol. 34, no. 1, pp. 189-192, 2012, in Chinese.

[10] X. Zhao, "The variation of fine structure of red clay under chemical corrosion," Journal of Transport Science and Engineering, vol. 31, no. 1, pp. 33-38, 2015, in Chinese.

[11] X.-B. Yang, Y. Huang, and T. Pan, "Mechanical characteristics of laterite contaminated by phosphorus," Hydrogeology \& Engineering Geology, vol. 43, no. 1, pp. 143-148, 2016, in Chinese.

[12] X. Zhang, Experimental Study on Acid and Alkali Contaminated Soil, Hohai University, Nanjing, China 2007, in Chinese.

[13] Z.-k. Liu and Y.-h. Li, "Influence of wetting- drying cycle action on mechanical properties of Guilin red clay under different $\mathrm{pH}$ value conditions," Journal of Natural Disasters, vol. 23, no. 5, pp. 107-112, 2014, in Chinese.

[14] O. Cuisinier, D. Deneele, and F. Masrouri, "Shear strength behaviour of compacted clayey soils percolated with an alkaline solution," Engineering Geology, vol. 108, no. 3-4, pp. 177-188, 2009.

[15] B. M. Sunil, S. Shrihari, and N. Sitaram, "Shear strength characteristics and chemical characteristics of leachate-contaminated lateritic soil," Engineering Geology, vol. 106, no. 1-2, pp. 20-25, 2009.

[16] Y. Yang, G. Wang, S. Xie, X. Tu, and X. Huang, "Effect of mechanical property of cemented soil under the different $\mathrm{pH}$ value," Applied Clay Science, vol. 79, pp. 19-24, 2013.

[17] M. L. Gualtieri, M. Romagnoli, S. Pollastri, and A. F. Gualtieri, "Inorganic polymers from laterite using activation with phosphoric acid and alkaline sodium silicate solution: mechanical and microstructural properties," Cement and Concrete Research, vol. 67, pp. 259-270, 2015.

[18] X.-H. Zhou and Y.-L. Liao, "Collochemistry character of the structure connection among red clay mineral grain," Journal of Gguizhou University of Technology (Natural Science Edition), vol. 33, no. 1, pp. 2-29, 2004, in Chinese.

[19] H.-H. Fan, L. I. Hong-liang, and Z Gao-wen, "Relation among dispersive mechanism, physical-chemical and mineral properties of clayey soil," Chinese Journal of Geotechnical Engineering, vol. 34, no. 9, pp. 1740-1745, 2012, in Chinese.

[20] L.-S. Tang, L. Zeng-Xian, and H. Guo-Yi, "Chemical action and mechanical effect of the material with abundant iron ion in red soils," Hydrogeology \& Engineering Geology, vol. 31, no. 4, pp. 45-49, 2004, in Chinese. 